\title{
PENGARUH TERAPI BERMAIN MEWARNAI TERHADAP KECEMASAN PADA ANAK PRASEKOLAH DENGAN HOSPITALISASI DI RS GRANDMED LUBUK PAKAM TAHUN 2020
}

\section{KUAT SITEPU ${ }^{1}$, LUCI RIANI BR GINTING ${ }^{2}$, RATNA BULAN ${ }^{3}$, SARMANA ${ }^{4}$, SAMUEL GINTING ${ }^{5}$.}

\author{
1,3,4,5 FAKULTAS KEPERAWATAN DAN FISIOTERAPI \\ 2 FAKULTAS KESEHATAN MASYARAKAT \\ INSTITUT KESEHATAN MEDISTRA LUBUK PAKAM \\ JL. SUDIRMAN NO. 38 LUBUK PAKAM KAB. DELIISERDANG, \\ SUMATERA UTARA \\ e-mail: ksitepu3@gmail.com
}

DOI $10.35451 / j k f . v 3 i 2.651$

\begin{abstract}
In general, children who experience hospitalization often experience separation from their parents, children who experience hospitalization must be able to adapt to the new environment and the people around them, the impact of this being cared for and hospitalized is fear around them, anxiety, trauma and anxiety. As indicated by WHO in 2018, practically $52.38 \%$ of kids experienced clinic treatment. In 2016 in Indonesia as numerous as 33.2\% of 1,425 kids encountered the effect of extreme hospitalization, $41.6 \%$ experienced moderate hospitalization. The Public Wellbeing Observation (SUSENAS), the quantity of preschool youngsters in Indonesia is $72 \%$ of the absolute populace of Indonesia, it is assessed that 35 for every 100 youngsters go through hospitalization and $45 \%$ of them experience nervousness. Types and Research Design This research is a quantitative examination that is experimental in nature with a Quasi-experimental approach with one group pretest and posttest design. The data analysis of the profitability of the bivariate calculation in this study used a paired sample test at a significance level of $95 \%$. The result of the research is the $p$ value = 0.000, where the $p$ value is $<0.05$. This shows that the difference before and after doing coloring play therapy on the anxiety of preschool children is very real.
\end{abstract}

Keywords: Coloring play therapy, anxiety, hospirtalization

\section{Pendahuluan}

Reaksi anak prasekolah terhadap hospitalisasi dapat ditunjukan dengan reaksi agresif, kemarahan, rekasi perlawanan, mengucapkan kata marah, tidak mau bekerjasam dengan tenaga Kesehatan serta hidupnya bergantung pada orang tua. Kecemasan pada anak pra sekolah mengalami gangguan Kesehatan dan opname di rumah sakit, merupakan bagian dari salah satu gangguan dimana kebutuhan emosional pada anak menjadi tidak nyaman dan tidak 
adekuat yaitu tidak terpenuhinya. Permasalahan seperti ini perlu dilkaukan tindakan sejak anak mengalami gangguan. Efek yang terjadi jika penanganannya terlambat dalam menangani kecemasan maka akan menolak segala perawatan dan pengobatan yang dilakukan. Keadaan seperti ini akan mempengaruhi interaksi terapi dan pada anak yang lemah (Zuhdatani, 2015 \& Kyle, Terri., \& Carman, Susan,2015).

Bermain dengan shading adalah latihan menunjuk ke arah mengurangi ketegangan dan mendapatkan kegembiraan pada anak-anak yang mengalami rawat inap dengan memberi mediasi sebagai garis-garis bayangan pada gambar. Tindakan dengan Pemberian siiniakan memberikan dampak pada fisik serta merangsang emosi kerangka limbik, jadi itu terjadi pengontrolan perilaku maladaptive di hypothalamus. Tindakan tersebut dilakukan dengan tujuan untuk mengetahui efek Latihan bermain dengan merwarnai terhadap prilaku maladaptive pada anak anak prasekolah antara 3 sampai 6 tahun yang mengalami hospitalisasi.

Pada umum nya anak-anak yang mengalami hospitalisasi sering kali mengalami perpisahan dengan orang tuanya ,anak yang mengalami hospitalisasi harus dapat beradaptasi dengan lingkungan baru dan orangorang di sekelilingnya, dampak dari ini anak dirawat dan hospitalisasi adalah ketakutan disekitarnya, kegelisahan, trauma dancemas (Kartinawati, Haryani \& Arif, 2015). Anak sakit yang dengan hospitalisasi sering mengartikan sebagian hukuman, kemudianmuncul rasa malu, takut, hal ini menjadikan anak bersifat agresif, marah, berontak, seringbertanya, tidak mau makan, tidak kooperatif hingga kehilangan control dan terbatasnya aktifitas yang membuat perawatan dirumah sakit bisa terhambat (Azizah \& Ernawati 2015).

Tinjauan Moneter Publik (SUSENAS) 2010 disutradarai oleh Sumayoko (2016), Jumlah anak usia prasekolah (3-6 tahun) adalah $72 \%$ dari seluruh penduduk Indonesia, anak muda menjalankan Rawat Inap di Poliklinik Kediri Babtis dengan total 35 orang per 100 individu dan 45\% mengalami ketegangan (Kholisatum 2013). Ini sejalan dengan penelitian yang diarahkan oleh Desita dan Febriana (2016) pada pasien anak dewasa 3-6 tahun diperoleh 10 orang anak (6\%) menunjukan respon terhadap hospitalisasi dengan kondisi menangis, takut, tidak membantu pejabat kesehatan, bakan selalu menanyakan kepada ibunya kapan bisa pulang kembali ke rumah, sedangkan 5 orang (3\%) menunjukan respon adaptif terhadap hospitaliasasi yaitu dengan menunjukkan respon kooperatif dengan petugas kesehatan dan mau minum obat.

Pengukuran Kesejahteraan menilai bahwa 3-5 juta anak di bawah 15 tahun rawat inap yang panjang secara konsisten. Saat anak-anak dirawat di rumahsakit, mereka pada umumnya akan mendapatkan pegangan di kiri keluarga dan merasa di iklim baru (Terri K dan Susan C, 2015). Di Jumlah anak usia prasekolah di Indonesia (3-5 tahun) dalam studi moneter Publik (SUSENAS) pada tahun 2001 menambahkan hingga 72\% dari total populasi Indonesia, diperkirakan 35 dari setiap 100 anak menjalani rawat inap (Sumaryoko, di Purwandari, 2016).

Menurut WHO (2018) didapatkan sebanyak hampir 52,38\% anak mengalami gangguan dan opname di klinik darurat. Pada tahun 2016 di Indonesia terdapat total $33,2 \% 1.425$ remaja mengalami efek rawat inap serius dan $41,6 \%$ mengalami rawat 
inap moderat. Sementara itu, Public Wellbeing Observation (SUSENAS) memperoleh jumlah anak-anak yang matang Prasekolah di Indonesia mewakili $72 \%$ dari seluruh penduduk Indonesia, dari 35 untuk setiap Diasumsikan bahwa 100 remaja yang menjalani rawat inap mewakili $45 \%$ dari mereka menghadapi ketegangan Selain membutuhkan perawatan khusus dibandingkan dengan kondisi pasien yang lainnya, waktu yang dibutuhkan untuk merawat korban anak beranjak dari 20\% - 45\% lebih banyak dari orang dewasa. Anak yang dirawat di klinik medis akan terkena dampaknya tentang kondisi fisik dan mental mereka (Wahyuni, 2016 \& Hockenberry 2016). Hasil pemeriksaan primer pada kerabat anak yang ditangani menemukan pada jam kunjungan menghitung jumlah kerabat yang telah ditentukan yang bertahan di klinik darurat juga dibatasi, kegugupan anak meningkat selama perawatan karena anak perlu diisolasi dengan orang-orang terdekatnya.Selain itu dari hasil wawancara singkat dengan orang tua kepada anak anak yang opname di rumah sakit menggungkapkan dari sejak pertama kali masuk dan dirawat anak sering menangis, terlihat gelisah, dan takut bilamana anaknya didekati oleh perawat dan pada saat dilakukan tindakan keperawatan, tetapi sekarang anaknya sudah takut lagi kecuali kalau ada tindakan tertentu yang akan diberikan. Berdasarkan data di atas penelita tertarik untuk melakukan penelitian ini yang berjudul "Pengaruh Terapi Bermain Mewarnai Terhadap Kecemasan Anak Prasekolah Dengan Hospitalisasi Di Rumah Sakit Grandmrd Lubuk Pakam Tahun 2020".

\section{METODE}

Penelitian ini termasuk penelitian dengan jenis kuantitatif dengan pendekatan quasi eksperiment dengan one group pretest dan posttest design yaitu suatu penelitian yang bertujuan untuk melihat adanya dampak dari perlakuan bermain shading ketidaknyamanan dengan rawat inap di anak-anak usia prasekolah dewasa (3-6 tahun) di klinik Grandmed Lubuk Pakam. Pemeriksaan ini diarahkan apa adanya membandingkan kecemasan pada kelompok intervensi sebelum dan sesudah diberikan intervensi.

\section{HASIL}

Berdasarkan penelitian yang telah dilakukan kepada 34 orang pasien yang menjadi responden diruang rawat inap di Rumah Sakit Grandmed Lubuk Pakam yang telah memenuhi syarat menjadi responden dengan ketentuan yang telah dibuat. Kriteria inklusi dari pada penelitian ini adalah anak usia 3- 6 tahun, anak yang di rawat inap di Rumah Sakit GrandMed, Anak dalam keadaan sadar dan tidak dalam keadaan koma yang di ruang rawat inap di Rumah Sakit Grandmed Lubuk Pakam. Pasien yang bersedia menjadi responden. Sedangkan Kriteria ekslusi pada penelitian ini adalah Anak yang bukan usia prasekolah dan anak yang mengalami gangguan motorik.

3.1 Kecemasan anak prasekolah sebelum tindakan terapi bermain mewarnai.

Tabel 1 Kecemasan anak pra sekolah sebelum tindakan terapi bermain mewarnai

\begin{tabular}{llll}
\hline No & Kecemasan & Jumlah & Persentase \\
\hline 1. & Sedang & 32 & $94.1 \%$ \\
2. & Berat & 2 & $5.9 \%$ \\
& Jumlah & 34 & $100 \%$ \\
\hline
\end{tabular}


Lebih dari 100 persen responden Mempersepsikan kecemasan sebelum dilakukan terapi bermain mewarnai dengan kategori kecemasan sedang sebanyak 32 orang (94.1\%).

\subsection{Kecemasan anak pra sekolah} sesudah tindakan terapi bermain mewarnai

Tabel 2 Kecemasan anak prasekolah sesudah tindakan terapi bermain mewarnai

\begin{tabular}{llll}
\hline No & Kecemasan & Jumlah & Persentase \\
\hline 1. & $\begin{array}{l}\text { Tidak } \\
\text { Cemas }\end{array}$ & 1 & $2.9 \%$ \\
2. & Ringan & 6 & $17.6 \%$ \\
3. & Sedang & 27 & 79.4 \\
\hline & Jumlah & 34 & $100 \%$ \\
\hline
\end{tabular}

Tabel 2 menunjukkan dari 34 responden yang tindakan terapi bermain mewarnai bahwa yang memilik kecemasan tidak cemas aa 1 orang $(2.9 \% 0$ dan kecemasan Ringan ada 6 orang $(17.6 \%)$ dan kecemasan sedang ada sebanyak 27 orang (79.4 $\%)$.

\subsection{Pengaruh terapi bermain} mewarnai terhadap kecemasan anak prasekolah dengan hospitalisasin

Tabel 3 Pengaruh terapi bermain mewarnai terhadap kecemasan anak prasekolah dengan hospitalisasi di Rumah Sakit Grandmed Lubuk Pakam.

\begin{tabular}{|c|c|c|c|c|c|c|}
\hline $\begin{array}{c}\text { Kecem } \\
\text { asan }\end{array}$ & $\begin{array}{c}\text { Mea } \\
\mathrm{n}\end{array}$ & $n$ & $\begin{array}{l}\text { Std. } \\
\text { Devi } \\
\text { ation }\end{array}$ & $\begin{array}{l}\text { Std.Err } \\
\text { or } \\
\text { Mean }\end{array}$ & & $\begin{array}{c}\text { p- } \\
\text { valu } \\
\text { e }\end{array}$ \\
\hline $\begin{array}{l}\text { Sebel } \\
\text { um }\end{array}$ & $\begin{array}{c}23.8 \\
5\end{array}$ & $\begin{array}{l}3 \\
4\end{array}$ & $\begin{array}{c}2.00 \\
2\end{array}$ & .343 & 100 & 0,00 \\
\hline $\begin{array}{c}\text { Sesud } \\
\text { sah }\end{array}$ & $\begin{array}{c}16.9 \\
1\end{array}$ & $\begin{array}{l}3 \\
4\end{array}$ & $\begin{array}{c}4.23 \\
1\end{array}$ & .726 & 100 & 1 \\
\hline Total & & & & & 100 & \\
\hline
\end{tabular}

Tabel 3 Menunjukkan pengaruh terapi bermain mewarnai terhadap kecemasan anak pra sekolah, rata rata kecemasan sebelum dilakukan terapi bermain mewarnai adalah 23.85 dengan standart deviasi 2.002 dan standar error mean adalah .343 dan rara - rata kecemasan anak pra sekolah sesudah dilakuakn terapi bermain mewarnai adalah 16.91 dengan standart deviasai 4.231 dan standar error mean adalah .726.

Hasil uji statistic menunjukkan nilai $p$ $=0.000$. Ha diterima jika Hasil analisis statistik didapatkan bahwa ada pengaruh terapi bermain mewarnai terhadap kecemasan anak pra sekolah dengan hospitalisasi di Rumah Sakit Grandmed lubuk pakam.

\section{PEMBAHASAN}

\section{Kecemasan anak pra sekolah sebelum tindakan terapi bermain mewarnai.}

Anak prasekolah yang mengalami hospitalisasi di RS Grandmed Lubuk Pakam diperoleh responden dengan cemas ringan sebanyak 6 orang $(17.6 \%)$ sedangkan cemas sedang sebanyak 27 orang (79.4\%) dan berdasarkan hasil penelitian terjadi perubahan kecemasan pada anak dengan hospitalisasi bahwa cemas berat tidak lagi dialami oleh anak dengan hospitalisasi. Hasil penelitian ini yang dilakukan oleh peneliti dengan berdasarkan acuan bahwa terjadi perubahan kecemasan terhadap anak prasekolah yang mengalami hospitalisasi dengan dilakukan terapi bermain mewarnai anak mendapatkan hiburan atau dapat mengekspresikan perasaannya melalui terapi mewarnai tersebut sehingga kecemasan anak berkurang.

\section{Kecemasan anak pra sekolah sesudah tindakan terapi bermain mewarnai.}

Hasil penelitian mengenai efek terapi bermain mewarnai pada kecemasan anak praseoklah dengan hospitalisasi yaitu rata-rata kecemasan 
anak sebelum dilakukan tindakan terapi bermain mewarnai sebesar 23.85 dan rata-rata kecemasan anak setelah dilakukan tindakan terapi bermain mewarnai sebesar 16,91 dengan standart devisi (SD) 4.231. Hasil uji statistic didapatkan nilai $p$ value $=0.000$, dimana $p<0,05$ maka dapat disimpulkan bahwa terdapat pengaruh terapi bermain mewarnai terhadap kecemasan anak prasekolah dengan gangguan hospitalisasi di RS Grandmed Lubuk Pakam Tahun 2020.

Terapi bermain yang bertujuaan mengekspresikan perasaan, keinginan dan fantasi serta ide-idenya. Ketika anak mengalami sakit dan dirawat dirumah sakit, anak akan mengalami bermacam-macam perasaan yang sangat menyenangkan. Anak belum dapat mengekspresikannya secara verbal. Disini peneliti menggunakan terapi bermain mewarnai menggunakan gambar untuk menurunkan kecemasan anak prasekolah selama hospitalisasi. (Supartini 2016, Rusmariana 2013 \& Winarsih, 2015), mewarnai merupakan permainan melalui buku gambar untuk mengembangkan kreatifitas pada anak untuk meminimalisir tingkatan stress dan kecemasan anak serta meningkatkan komunikasi terhadap anak.

Hasil Penelitian diatas sejalan dengan penelitian yang dilaksanakan oleh Devi Purwati (2017) yang berjudul pengaruh terapi bermain mewarnai gambar terhadap tingkat kecemasan anak prasekolah selama Hospitalisasi di RSUD Kota Madiun dari 21 responden rata-rata kecemasan anak sebelum diberikan intervensi 7 anak (33.3\%) Mengalami cemas berat dan setelah diberikan intervensi 15 anak $(71.4 \%)$ mengalami penurunan cemas menjadi ringan. Pembahasan diatas dapatdisimpulkan bahwa terapi bermain mewarnai gambar terhadap tingkat kecemasan anak prasekolah selama hospitalisasi memberikan pengaruh yang signifikan terhadap perubahan anak yang mengalami hospitalisasi.

\section{KESIMPULAN}

Berdasarkan hasil uji statistic dan pembahasan yang telah ada di bab sebelumnya dapat disimpulkan bahwa ada pengaruh terapi bermain mewarnai terhadap kecemasan anak prasekolah dengan hospitalisasi di RS Lubuk Pakam Tahun 2020.

Berdasarkan hasil penelitian dari 34 orang responden sebelum dilakukan terapi bermain mewarnai dengan menggunakan lembar kuisioner bahwa mayoritas responden mengalami cemas sedang sebanyak 32 orang dengan presentase $94.1(\%)$.

Berdasarkan hasil penelitian dari 34 orang responden setelah dilakukan terapi bermain mewarnai dengan menggunakan lembar kuisioner bahwa mayoritas responden mengalami cemas ringan sebanyak 6 orang dengan presentase $(17.6 \%)$

Berdasarkan hasil penelitian dari 34 orang responden sebelum dan sesudah dilakukan terapi terjadi peningkatan signifikan terhadap perubahan kecemasan anak sebelum dilakukan terapi dengan sesudah dilakukan terapi bermain dari sebelum dengan 32 orang anak yang mengalami sedang dan berat 2 orang anak dan berubah menjadi tidak cemas 1 orang,ringan 6 orang dan sedang 27 orang setelah dilakukan terapi bermain mewarnai.

\section{DAFTAR PUSTAKA}

Azizah \& Ernawati (2015). PENGARUH TERAPI BERMAIN WAIKE TERHADAP KECEMASAN AKIBAT HOSPITALISASI DI RSUD DR. MOEWARDI. 
Devi Purwanti. (2015). PENGARUH PEMBERIAN TERAPI BERMAIN ANAK PRASEKOLAH SELAMA HOSPITALISASI DI RSUD KOTA MADIUN.

Febriana, Desita. (2016). KAJIAN STRES HOSPITALISASI TERHADAP PEMENUHAN POLA TIDUR ANAK USIA PRASEKOLAH DI RUANG ANAK RS BAPTIS KEDIRI

Hockenberry \& Wilson (2015) WONG'S NURSING CARE OF INFANTS' AND CHILDREN Edition 9. St. Lous, Missouri: ELSEVIER MOSBY.

Kyle, Terri., \& Carman, Susan. (2015). BUKU AJAR KEPERAWATAN PEDIATRI Edisi 2. Jakarta : Buku Kedokteran EGC.

Purwandari, Haryatiningsih. (2009). PENGARUH TERAPI SENI TERHADAP KECEMASAN ANAK USIA SEKOLAH SELAMA HOSPITALISASI DI RSMS. Skripsi. Tidak diterbitkan. Depok: Fakultas Ilmu Keperawatan Universitas Indonesia.

Rusmariana, A., Faridah, N., \& Ariyani, R. (2013). EFEKTIFITAS BERMAIN MENGGAMBAR TERHADAP KECEMASAN ANAK USIA PRASEKOLAH AKIBAT HOSPITALISASI. Journal Kesehatan, Volume V, No. 2.

Supartini, Y. (2015). BUKU AJAR KONSEP DASAR KEPERAWATAN ANAK. Jakarta : EGC.

Winarsih, D, B. (2015). HUBUNGAN PERAN SERTA ORANG TUA DENGAN DAMPAK HOSPITALISASI PADA ANAK USIA PRASEKOLAH DI RSUD KARTINI JEPARA. Thesis. Depok : Universitas Indonesia.

Wong, D.L. (2016). BUKU AJAR KEPERAWATAN PEDRIATIK. Jakarta : EGC

Zuhdatani, Munfarikatuz. (2015). HUBUNGAN DUKUNGAN KELUARGA DENGAN TINGKAT KECEMASAN AKIBAT
HOSPITALISASI PADA ANAK USIA PRASEKOLAH (3-6 TAHUN) DI RUANG ANAK RSUD BALUNG. Skripsi. Diakses melalui https://Journal.umm.ac.id pada 8 Juli 2020. 